\title{
INTEGRATED MANAGEMENT: CHRONIC KIDNEY DISEASE, DIABETES MELLITUS, HYPERTENSION
}

\author{
Sarala Naicker
}

Division of Nephrology, University of the Witwatersrand, Charlotte Maxeke Johannesburg Academic Hospital Johannesburg South Africa.

\begin{abstract}
The increasing burden of chronic kidney disease and end stage kidney failure presents a challenge for both developed and emerging countries. While dialysis and transplantation consumes an ever-increasing proportion of the health budget in countries such as the United States, Japan and Taiwan, there is limited availability of these expensive therapies in the majority of emerging countries and more so in African nations.

Aims: To review the prevalence, causes and integrated strategies for treatment and prevention of end stage renal disease (ESRD) in Sub-Saharan Africa (SSA).

Materials and Methods: Review of literature and information received from colleagues in Africa.

Results: Approximately $70 \%$ of the least developed countries of the world are in SSA. Rapid urbanisation is occurring in many parts of the continent, contributing to overcrowding and poverty. While infections and parasitic diseases are still the leading cause of death in Africa, non-communicable diseases are coming to the forefront. There is a continuing "brain drain" of healthcare workers (physicians and nurses) from Africa to more affluent regions, resulting in large rural areas of Africa having no health professionals to serve these populations. There are no nephrologists in many parts of SSA; the numbers vary from 0.5 per million population (pmp) in Kenya to 0.6 pmp in Nigeria, 0.7 pmp in Sudan and $1.1 \mathrm{pmp}$ in South Africa.

Chronic kidney disease (CKD) affects mainly young adults aged 20-50 years in SSA and is primarily due to hypertension and glomerular diseases. HIV-related chronic kidney disease is assuming increasing prominence and often presents late, with patients requiring dialysis. Diabetes mellitus affects 9.4-million people in Africa. The prevalence of diabetic nephropathy is estimated to be $6-16 \%$ in SSA. The current dialysis treatment rate is $<20 \mathrm{pmp}$ (and nil in many countries of SSA), with in-centre haemodialysis the modality of renal replacement therapy (RRT) for the majority. Transplantation is carried out in a few SSA countries: South Africa, Sudan, Nigeria, Mauritius, Kenya, Ghana and Rwanda, with most of the transplants being living donor transplants, except in South Africa where the majority are from deceased donors. Prevention programmes are in their infancy in most of SSA, due to lack of personnel and resources.

Conclusion: Chronic kidney disease care is especially challenging in SSA, with large numbers of ESRD patients, inadequate facilities and funding, and lack of national or regional registries. Integrated management of CKD and its risk factors is necessary to impact on the burden of ESRD.
\end{abstract}

Key words: Sub-Saharan Africa - end stage renal disease - chronic kidney disease - renal replacement therapy.

Disclosure: There is no conflict of interest.

Chronic kidney disease (CKD) should be viewed as a continuum, ranging from risk factors causing CKD (diabetes

Address of Correspondence: Prof. Sarala Naicker, Division of Nephrology, University of the Witwatersrand, Charlotte Maxeke Johannesburg Academic Hospital, 7 York Road, Parktown, 2193, Johannesburg, South Africa

E-mail: Saraladevi.Naicker@wits.ac.za 
mellitus, hypertension, glomerular disease) and resulting in the reduction of kidney function, microalbuminuria, macroalbuminuria, end stage renal failure (ESRF) and death $^{1}$.

In recent years, major social and demographic changes have taken place in Africa, with large numbers of rural Black populations migrating to the cities, adopting a more western lifestyle, and being exposed to vascular risk factors with respect to diet, smoking habits, and level of physical activity. Recent hospital morbidity and intensive care unit statistics in South Africa indicate that the prevalence of coronary heart disease (CAD) in urban Blacks is increasing ${ }^{2}$.

While the burden of infections presents an enormous challenge in Sub-Saharan Africa (SSA), non-communicable diseases also constitute a major threat to the populations of Africa. This "double burden" poses a public health and economic burden to developing countries. Infections and parasitic diseases are still the leading cause of death in Africa, with over 5.5-million deaths in 2005 and over 2-million deaths due to HIV/AIDS. Non-communicable diseases are coming to the forefront with over 2.4-million deaths in $2005^{3}$. While communicable diseases are the leading cause of death in low income countries, chronic diseases such as ischaemic heart disease and stroke feature at number two and four respectively ${ }^{4}$ and were the leading causes of death in South Africa in the previous decade 5 . A more recent study showed that stroke and heart disease were the two leading causes of death in 15-64-year-old Black South African men and women for the period 19992006, with death from kidney disease featuring as the fifth leading cause of death in this age group in $2006^{6}$.

\section{Chronic kidney disease and end stage renal disease}

The lack of renal registries means that there are no reliable statistics about the prevalence of chronic kidney disease $(\mathrm{CKD})$ and end stage renal disease (ESRD) in the majority of African countries. Calculations suggest that CKD must be in the range of $200-300$ per million of the general population.

Chronic kidney disease is prevalent in Nigeria, accounting for $8-12 \%$ of hospital admissions ${ }^{7}$, and affects mainly young adults aged $20-50$ years in SSA and is primarily due to hypertension and glomerular diseases. However, in developed countries CKD presents in middle-aged and elderly patients and is predominantly due to diabetes mellitus and hypertension.

Chronic kidney disease has been shown to confer increased risk for cardiovascular (CV) death. The Women's Health Study of $\pm 40,000$ healthcare workers aged $>45 \mathrm{y}$ in the United States reported that 1,199 CV events and 856 deaths occurred over 12 years. There were 1,315 women with $\mathrm{eGFR}<60 \mathrm{ml} / \mathrm{min} / 1.73 \mathrm{~m} 2$ and an increased risk of CV death with hazard ratio (HR) of 1.68. Average demographics of the study population (age 55, total cholesterol $5.5 \mathrm{mmol} / \mathrm{l}$, HDL cholesterol $1.4 \mathrm{mmol} / 1$, not diabetic, non-smoker, systolic BP $124 \mathrm{mmHg}$ ) suggested that the increased $\mathrm{CV}$ risk was due to a decrease in renal function ${ }^{8}$.

The Framingham study showed increased CV and all cause mortality according to proteinuria status in men and women aged 35-74 years over 16 years of follow up?.

\section{Major risk factors for chronic kidney disease in Africa}

\section{Hypertension}

In the South African Demographic Health Survey of over 13,000 adults, hypertension prevalence was $21.3 \%$, with $<50 \%$ treated and $<1 / 3$ controlled ${ }^{5}$. Hypertension is a leading cause of $\mathrm{CKD}$ in SSA ranging from $25 \%$ in Senegal, $29.8 \%$ in Nigeria, $45.6 \%$ in South Africa and $48.7 \%$ in Ghana, especially in Black patients ${ }^{10}$. Hypertension affects about $25 \%$ of the adult population and is the cause of ESRD in $21 \%$ of patients on renal replacement therapy in South Africa ${ }^{11}$. The clinical pattern of hypertension in hospitalised patients takes a rapid course with uraemia and death, frequently from cerebral haemorrhage. Malignant hypertension was an important cause of morbidity and mortality among urban Black South Africans with hypertension accounting for $16 \%$ of all hospital admissions ${ }^{12}$ and seems to be of lesser frequency in the present era.

\section{Glomerulonephritis}

Glomerular disease is common in Africa and is a major cause of ESRD in reports from SSA. Reports from different areas of Africa display differences in the prevalence of patterns of glomerular injury. For example, in Nigerian children with nephrotic syndrome, membranoproliferative patterns on biopsy predominate, whereas in series from South Africa FSGS seems to be commonest ${ }^{13,14}$. Although epidemiologic data from many areas in Africa is sparse, the incidence of glomerular disease, particularly nephrotic syndrome, seems to be many times higher in Africa. Glomerular disease is more prevalent in Africa and seems to be of a more severe form than that found in western countries, and is characterised by poor response to treatment and progression to renal failure.

One success story is the impact of hepatitis B vaccination in South Africa; prior to the availability of the vaccine, hepatitis B virus (HBV) infections accounted for over $80 \%$ of membranous nephropathy in Black children ${ }^{15}$. Following vaccination, there were no cases of membranous nephropathy due to HBV reported in the 0-4 year age group $^{16}$. 


\section{HIV chronic kidney disease}

HIV infection is epidemic in SSA. The number of new infections is now declining, with increasing numbers of patients on anti-retroviral therapy ${ }^{17}$. Data on the prevalence of HIV-related glomerular disease in Africa is scarce. This relates to the late presentation in Africa of patients with the disease; often patients are dialysis-requiring at presentation. Reported prevalence of CKD in HIV-infected ART-naïve patients in SSA ranges from $6-45 \%$ (Table 1) ${ }^{18}$. Screening studies in South Africa reported proteinuria in 5.5-6\%, with HIV-associated nephropathy (HIVAN) on biopsy in $5-83 \%{ }^{19}$,

${ }^{20}$. Recent studies showed that the risk for HIVAN is linked to the MYH9 gene polymorphism, with the risk variant accounting for all or nearly all of the increased risk for FSGS $(80 \%)$ and HIV-associated collapsing glomerulopathy $(100 \%)$ that characterise African Americans ${ }^{21,22}$. The APOL1 variant was reported to be strongly associated with the collapsing glomerulopathy of HIV-associated nephropathy in African Americans ${ }^{23}$. An escalating burden of HIV CKD may be anticipated, with increasing life expectancy on ART, ageing of HIV-infected populations and nephrotoxicity of the various drugs used in this population. Following ART, renal function improved ${ }^{24}$, with renal survival dependent on virological response to therapy ${ }^{25}$. Lack of response was attributed to a high index of chronic damage in a study of 61 patients with HIVAN presenting with advanced CKD at the time of diagnosis and initiation of ART, $56 \%$ of whom reached ESRD in a median time of 4.2 years $^{26}$. The response of both microalbuminuria (MA) and proteinuria to ART was rapid and sustained, resolving to normal limits within 3-6 months ${ }^{27}$.

\section{Diabetes mellitus}

There are 135-million diabetics worldwide, with a projected increase to 300 -million by 2025 and to increase by $170 \%$ in developing countries $( \pm 40 \% \text { in developed countries })^{28}$. Diabetes mellitus affects 9.4-million people in Africa. The estimated increase in diabetes mellitus in Africa is anticipated to be $12.7-$ million, an increase of $140 \%$, by 2025 . The prevalence of diabetic nephropathy is estimated to be 6-16\% in $\mathrm{SSA}^{29}$. Forty percent of diabetics are at risk of overt nephropathy. Diabetic patients with renal disease have a five to six-fold increased mortality rate compared to diabetic patients with no signs of renal disease, or healthy subjects. Cardiovascular risk is increased in diabetics according to the level of proteinuria ${ }^{30}$ and presence of hypertension. ${ }^{32}$ Renoprotective strategies have been well-described and include glycaemic control, blood pressure control, antiproteinuric drugs (rennin angiotensin system blockade and aldosterone antagonists), cessation of smoking, a diet low in salt and saturated fats, exercise and weight control and antiplatelet therapy (Table 2).

\section{Resources for nephrology care}

There is a continuing "brain drain" of healthcare workers (physicians and nurses) from Africa to more affluent regions $^{32}$, resulting in large rural areas of Africa having no health professionals to serve these populations. Table 3 shows the distribution of physicians and nephrologists in a spectrum of SSA countries and their corresponding rates of renal replacement therapy (RRT). There are no nephrologists in many parts of SSA; the numbers vary from $0.5 \mathrm{pmp}$ in Kenya to 0.6 per million population ( $\mathrm{pmp}$ ) in Nigeria, 0.7 pmp in Sudan, $1.1 \mathrm{pmp}$ in South Africa ${ }^{33}$. The United States had 16.7 nephrologists pmp and optimal numbers are 30 nephrologists pmp.

\section{Renal replacement therapy}

The availability of RRT is limited in much of Sub-Saharan Africa due to high costs and a shortage of skilled personnel, and is responsible for the high rates of morbidity and mortality. Most dialysis centres are situated in cities, placing a further burden on patients who often have to travel long distances to get treatment. In-centre haemodialysis is the modality of RRT for the majority of African countries. Many patients are under-dialysed; only $20 \%$ of patients in a Nigerian centre could afford to have dialysis three times a week, and $70 \%$ could only afford it once a week ${ }^{3}$. As the majority are self-funded, very few are able to sustain chronic dialysis beyond six months.

Renal replacement therapy was accessed by approximately 1.8 -million people worldwide in 2004; less than $5 \%$ of the dialysis population was from SSA. The current dialysis treatment rate ranges from $<20$ per million population (pmp) for most of SSA (and nil in many countries of SSA) to $421 \mathrm{pmp}$ in Egypt; the corresponding figures for Japan being 1,940 pmp, USA 1,090 pmp and Germany 800 pmp. Dialysis rates were $45 \mathrm{pmp}$ for haemodialysis (HD) and 23 pmp for CAPD in South Africa; 46 pmp for HD and 3 pmp for CAPD in Sudan and $7.5 \mathrm{pmp}$ for HD and $1.2 \mathrm{pmp}$ for CAPD in Kenya compared to 421 pmp for HD and 0.3 pmp for CAPD in Egypt, 650 pmp for HD and 20 pmp for CAPD in Tunisia ${ }^{33}$. Availability of CAPD is limited in SubSaharan Africa because of the high cost of dialysis fluids and a perception of a high rate of peritonitis. The average cost of haemodialysis in Africa is $\$ 100$ per session. The annual costs of CAPD are equivalent to that of in-centre haemodialysis. Transplantation is carried out in a few SSA countries: South Africa, Sudan, Nigeria, Mauritius, Kenya and Ghana, with most of the transplants being living donor transplants, except in South Africa where deceased donor transplants are carried out to a greater extent $(80 \%$ deceased donors and $20 \%$ living donors respectively). Deceased donation is hampered in many countries by a lack of a legal framework governing brain death, and religious and social constraints. The transplant rate in Africa averages $4 \mathrm{pmp}$ and is $9.2 \mathrm{pmp}$ in South Africa ${ }^{35}$.

Funding for RRT is primarily private in much of Africa, with the governments of only a few countries providing RRT for small number of patients (e.g. Cameroon, Mali, Mauritius, Rwanda, Sudan, South Africa); indigent South Africans are able to access chronic dialysis at governmental cost only if they are eligible for transplantation. In many African 
countries, chronic dialysis is not sustainable, with patients unable to afford dialysis beyond the first 2-3 months.

\section{Strategies for Africa}

The above highlights the important facts of chronic disease epidemiology in Africa with tremendous public health ramifications. Hypertension, diabetes, coronary heart disease and ESRD are on the verge of becoming an epidemic in Africa with urbanisation. Treatment for all affected is beyond the reach of most countries in Africa. The only cost effective and sustainable means is prevention. How can Africa prevent or curtail the increasing prevalence of these non-communicable conditions?

\section{Primary prevention strategies}

Effective prevention and management of chronic conditions requires a co-ordinated, comprehensive healthcare system involving self-management and regular follow-up. Public education at an early stage - at schools - and on a continual basis, with active media participation to promote healthy living, as well as financial and other incentives, would result ultimately in healthier populations. Countries like South Africa have legislated successfully against smoking in public places.

Immunisation has played an important role in disease prevention. Inclusion of hepatitis B vaccination in the extended programme of immunisation in South Africa in 1995 has impacted on the prevalence of membranous nephropathy due to this aetiology in children.

\section{Secondary prevention strategies}

The majority of patients with CKD present with terminal uraemia, requiring emergency dialysis. Screening of high-risk populations for CKD (Table 4) is a strategy that should be implemented, directed at patients with hypertension, diabetes mellitus, proteinuria, HIV infection (Table 5), the elderly, and those with a family history of chronic kidney disease. Simple screening tests such as urinalysis and measurement of serum creatinine, with calculation of GFR are important initial investigations to identify CKD. It is important for different regions to validate formulae for estimating GFR for their populations.

\section{Conclusion}

Provision of RRT is especially challenging in SSA. Nephrologists and physicians are faced with large numbers of ESRD patients, inadequate facilities, funding and support. While prevention strategies are recognised as optimal therapy in managing CKD, it is still in its infancy in much of SSA, mainly due to lack of healthcare workers and funding. Prevention of renal disease by early detection of its risk factors, delaying the progression of $\mathrm{CKD}$ in those patients with renal damage and attending to cardiovascular risk factors, as well as timely planning for RRT in those patients reaching ESRD, is essential in the integrated management of $\mathrm{CKD}$ and its risk factors, and is necessary to impact on the burden of ESRD.

\section{REFERENCES}

1. Cirillo M, Laurenzi M, Panarelli P, Mancini M, Zanchetti A, De Santo NG, Relation of Urinary Albumin Excretion to Coronary Heart Disease and Low Renal Function: Role of Blood Pressure, Kidney Int, 2004, Jun; 65(6): 2290-7.

2. Sliwa K, Wilkinson D, Hansen C, Ntyintyane L, Tibazarwa K, Becker A, Stewart S, Spectrum of Heart Disease and Risk. Factors in a Black Urban Population in South Africa (the Heart of Soweto Study): a cohort study, Lancet, 2008, Mar 15; 371(9616): 915-22.

3. World Health Report 2008, http://www.who.int/ whr/2008/en/index.html, accessed 1 August 2009.

4. World Health Report 2009, http://www.who.int, accessed 15 May 2010.

5. Steyn, K, Gaziano TA, Bradshaw D, Laubscher R, Fourie J, Hypertension in South African Adults: Results from the Demographic and Health Survey, 1998, J Hypertens, 2001, 19(10): 1717-1725.

6. Mayosi BM, Flisher AJ, Lalloo UG, Sitas F, Tollman SM, Bradshaw D, The Burden of Non-communicable Diseases in South Africa, Lancet, 2009, 374: 1023-31.

7. Akinsola, A, Adelekun T, Arogundade F, Sanusi A, Magnitude of the Problem of CRF in Nigerians, African Journal of Nephrology, 2004, 8: 24-26.

8. Kurth T, de Jong PE, Cook NR, Buring JE, Ridker PM, Kidney Function and Risk of Cardiovascular Disease and Mortality in Women: a prospective cohort study, BMJ, 2009, 338: b2392-2398.

9. Arnlöv J, Evans JC, Meigs JB, et al, Low-grade Albuminuria and Incidence of Cardiovascular Disease Events in Nonbypertensive and Nondiabetic Individuals: the Framingham Heart Study, Circulation, 2005, Aug 16; 112(7): 969-975.

10. Arogundade FA, Barsoum RS, CKD Prevention in SubSabaran Africa: a Call for Governmental, Nongovernmental, and Community Support, Am J Kidney Dis, 2008, 51(3): 515-523.

11. Naicker S, End Stage Renal Disease in Sub-Saharan and South Africa, Kidney Int Suppl, 2003, (83): S119-122.

12. Veriava Y, du Toit E, Lawley CG, Milne FJ, Reinach SG, Hypertension as a Cause of End Stage Renal Failure in South Africa, J Hum Hypertens, 1990, 4(4): p379-383. 
13. Asinobi AO, Gbadegesin RA, Adeyemo AA, et al, The Predominance of Membranoproliferative Glomerulonephritis in Childhood Nephrotic Syndrome in Ibadan, Nigeria, West Afr J Med, 1999, 18(3): 203-206.

14. Bhimma R, Coovadia HM, Adhikari M, Nephrotic Syndrome in South African Children: Changing Perspectives over 20 years, Pediatr Nephrol, 1997, 11(4): 429-434.

15. Wiggelinkhuizen J, Sinclair-Smith C, Membranous Glomerulonephropathy in Childhood, S Afr Med J, 1987, 72(3): 184-187.

16. Bhimma R, Coovadia HM, Adhikari M, Connolly CA, The Impact of the Hepatitis B Virus Vaccine on the Incidence of Hepatitis B Virus-associated Membranous Nephropathy, Arch Pediatr Adolesc Med, 2003, 157(10): 1025-1030.

17. UNAIDS report 2010.

18. Naicker S, Fabian J, Risk Factors for the Development of Chronic Kidney Disease with HIV/AIDS, Clin Nephrol, 2010, Nov, 74 Suppl 1: S51-56.

19. Han TM, Naicker S, Ramdial, PK, Assounga AG, A Cross-sectional study of HIV-seropositive Patients with Varying Degrees of Proteinuria in South Africa, Kidney Int, 2006, 69(12): 2243-2250.

20. Fabian J, Proteinuria in HIV-infected Individuals, MMed thesis University of the Witwatersrand, 2008.

21. Kopp JB, Smith MW, Nelson GW,et al, MYH9 is a Major Effect Risk Gene for Focal Segmental Glomerulosclerosis, Nat Genet, 2008, 40: 1175-1184.

22. Kao WH, Klag MJ, Meoni LA, et al, MYH9 is Associated with Nondiabetic End Stage Renal Disease in African Americans, Nat Genet, 2008, 40(10):1185-92.

23. Tzur S, Rosset S, Shemer R, et al, Missense Mutations in the APOL1 Gene are Highly Associated with End Stage Kidney Disease Risk Previously Attributed to the MYH9 Gene, Hum Genet, 2010, Sep, 128(3): 345-350.

24. Stöhr W, Walker AS, Munderi P, et al, Estimating Glomerular Filtration Rate in HIV-infected Adults in Africa: Comparison of Cockecroft-Gault and Modification of Diet in Renal Disease Formulae, Antivir Ther, 2008, 13(6): 761-70.
25. Atta MG, Gallant JE, Rahman MH, et al, Antiretroviral Therapy in the Treatment of HIV -associated Nephropathy, Nephrol Dial Transplant, 2006, Oct, 21(10): 28092813.

26. Post FA, Campbell LJ, Hamzah L, et al, Predictors of Renal Outcome in HIV-associated Nephropathy, Clin Infect Dis, 2008, 46(8): 1282-1289.

27. Fabian J, Naicker S, Venter WD, et al, Urinary Screening Abnormalities in Antiretroviral-naïve HIVInfected Outpatients and Implications for Management - a Single-centre Study in South Africa, Ethn Dis, 2009, Spring, 19 (1 Suppl 1): S1-80-85.

28. World Health Report 1997.

29. Amos, AF, McCarty DJ, Zimmet P, The Rising Global Burden of Diabetes and its Complications: Estimates and Projections to the Year 2010, Diabet Med, 1997, 14 Suppl 5: S1-85.

30. Ostgren CJ, Lindblad U, Melander A, Råstam L, Survival in Patients with Type 2 Diabetes in a Swedish Community: Skaraborg Hypertension and Diabetes Project, Diabetes Care, 2002, Aug, 25(8): 1297-1302.

31. Bøg-Hansen E, Lindblad U, Ranstam J, Melander A, Råstam L, Impaired Glucose Metabolism and Obesity in Swedish Patients with Borderline Isolated Systolic Hypertension: Skaraborg Hypertension and Diabetes Project, Diabetes Obes Metab, 2001, Feb, 3(1): 25-31.

32. Eastwood JB, Conroy RE, Naicker S, West PA, Tutt RC, Plange-Rhule J, Loss of Health Professionals from Sub-Saharan Africa: the Pivotal Role of the UK, Lancet, 2005, 365(9474): 1893-1900.

33. El Matri, A, ESRD in Africa, in AFRAN congress, Feb 2007, Khartoum.

34. Bamgboye EL, End Stage Renal Disease in Sub-Saharan Africa, Ethn Dis, 2006, 16(2 Suppl 2): pS2-5-9.

35. Naicker S, End Stage Renal Disease in Sub-Saharan Africa, Ethn Dis, 2009, 19: S1-13-15. 
Table 1. Prevalence of HIV Chronic Kidney Disease

\begin{tabular}{|c|c|c|c|}
\hline \multicolumn{2}{|c|}{ Sub-Saharan Africa } & \multicolumn{2}{|l|}{ Global } \\
\hline Country & Prevalence (\%) & Country & Prevalence $(\%)$ \\
\hline South Africa & $5.5-6$ & United States & $3.5-12$ \\
\hline Nigeria & 38 & $\begin{array}{l}\text { Europe, Israel, } \\
\text { Argentina }\end{array}$ & $3.5-4.7$ \\
\hline Cote d'Ivoire & 26 & Hong Kong & 18 \\
\hline Tanzania & 28.4 & Brazil & $1.1-5.6$ \\
\hline Kenya & 25 & Switzerland & 18 \\
\hline Uganda & $20-48.5$ & India & 27 \\
\hline Zambia & 33.5 & Iran & 20 \\
\hline
\end{tabular}

Table 2. Renoprotection in Diabetes Mellitus

- Glycaemic control: $\mathrm{HbA} 1 \mathrm{C}<7 \%$

- Blood pressure control <130/80

- Anti-proteinuric agent:

- RAS blockade (ACEI; ARB)

- Aldosterone antagonists

- Other measures:

- Dietary: limit salt and saturated fats

- Stop smoking

- Lipid lowering

- Exercise and weight control

- Antiplatelet therapy 
Table 3. Distribution of Physicians, Nephrologists and Renal Replacement Therapy in Some Sub-Saharan African Countries

\begin{tabular}{|c|c|c|c|c|c|c|}
\hline Country & \multicolumn{2}{|c|}{$\begin{array}{l}\text { Physicians } \\
\text { No Density } / 10^{4}\end{array}$} & \multirow{2}{*}{$\begin{array}{l}\text { Neph } \\
\text { No PMP } \\
700.6\end{array}$} & \multicolumn{3}{|c|}{$\begin{array}{l}\text { RRT } \\
\text { HD CAPD TP } \\
\text { No PMP No PMP No/year }\end{array}$} \\
\hline Nigeria & 34923 & 3 & & 10008 & 0 & 70 \\
\hline Ghana & 3240 & 2 & 20.1 & 352 & 0 & 0 \\
\hline Senegal & 594 & $<1$ & 20.2 & 504.2 & 261 & 0 \\
\hline Sudan & 11083 & 3 & 250.7 & 161046 & 1113 & 74 \\
\hline Kenya & 4506 & 1 & 150.5 & 2607.5 & 301.2 & 10 \\
\hline Rwanda & 432 & $<1$ & 1 & 0 & 303.7 & 18 \\
\hline South Africa & 34829 & 8 & 501.1 & 207045 & 105823 & 240 \\
\hline
\end{tabular}

Abbreviations: $\mathrm{No}=$ number; $\mathrm{Neph}=$ nephrologists; RRT $=$ renal replacement therapy; $\mathrm{HD}=$ haemodialysis; $\mathrm{CAPD}=$ continuous ambulatory peritoneal dialysis; $\mathrm{TP}=$ transplants; $\mathrm{PMP}=$ per million population

Table 4. Screening for Chronic Kidney Disease

- High risk

- Hypertension

- Diabetes Mellitus

- HIV

- Family history of chronic kidney disease

- Older age group

- Screening tests

- Urine: protein creatinine ratio; haematuria

- Serum creatinine $\rightarrow$ eGFR 
Table 5. Recommendation: Screening for HIV Chronic Kidney Disease

- All patients diagnosed with HIV infection should be screened for proteinuria and kidney function at presentation, and annually if high risk

- High risk for HIV-related nephropathy

- African descent

- Low CD4 counts

- High viral loads

- Patients with DM, HPT, HCV co-infection

$\circ 1^{\circ} / 2^{\circ}$ relative with ESRD $(5.4 \mathrm{x}$ increased risk)

Adapted from Gupta et al, Clin Infect Dis, June 2005 